\title{
Motivos de lo siniestro en Trono de Sangre (Akira Kurosawa, 1957)
}

Lorenzo J. Torres Hortelano|lorenzojavier.torres.hortelano@urjc.es Universidad Rey Juan Carlos

Palabras clave

"Kurosawa", "Trono de sangre", "lo siniestro", "lo ominoso", "Freud”, "Trías"

Sumario

.1. Introducción.

2. Estado de la cuestión y Método.

3. Análisis y Resultados;

3.1. Primer motivo: malos presagios;

3.2. Primera visita a la bruja/araña (motivo de

lo inanimado viviente);

3.3. Tercer motivo (I): araña humana;

3.4. Tercer motivo (II): ¿a qué suena una araña?;

3.5. Quinto motivo (I): amputaciones;

3.6. Cuarto motivo: dejà vu;

3.7. Tercer motivo (III): cuando el bosque camine;

4. Discusión y Conclusiones.

5. Bibliografía;

6. Filmografía.

\section{Resumen}

En este artículo analizamos textualmente algunas secuencias claves de Trono de sangre (Kumonosu-jō, Kurosawa, 1957) centrándonos en cómo emerge paulatinamente lo siniestro en el relato. En cuanto al concepto de lo siniestro, seguimos tanto la teorización que Freud propuso en su célebre artículo de 1919 "Lo ominoso", como la lectura posterior que realizó Trías proponiendo unos motivos de los siniestro-que iremos localizando en la película-, así como la de González Requena en torno al mismo tema. La pregunta que guiará nuestro análisis es si lo siniestro surge o retorna de lo familiar como algo reprimido, como apunta Freud (y Trías), o si, como afirma González Requena, lo siniestro es más bien algo rechazado o recusado. ¿Hay en Trono de sangre un secreto que requería permanecer oculto en el alma del protagonista y que sería revelado por la influencia de la araña femenina? $\mathrm{O}$ ¿es el propio héroe el que, extraviado por su ambición, cae en la tela de araña?

\section{Cómo citar este texto:}

Lorenzo J. Torres Hortelano (2021): Motivos de lo siniestro en Trono de Sangre (Akira Kurosawa, 1957) en Miguel Hernández Communication Journal, Vol. 12 (1), pp. 159 a 179. Universidad Miguel Hernández, UMH (Elche-Alicante). DOI: https://doi. org/10.21134/mhcj.v12i.1141 


\section{Reasons for the sinister in Throne of Blood (Akira Kurosawa, 1957)}

Lorenzo J. Torres Hortelano|lorenzojavier.torres.hortelano@urjc.es Universidad Rey Juan Carlos

Keywords

"Kurosawa", "Throne of Blood", "the sinister", "the ominous", "Freud", "Trías"

Summary

1. Introduction.

2. State of the question and Method. Analysis and Results;

3.1. First motif: bad omens

3.2. First visit to the witch/spider (living inanimate motif)

3.3. Third motif (I): human spider

3.4. Third motif (II): what does a spider sound like;

3.5. Fifth motif (I): amputations

3.6. Third motif (III): when the forest walks

4. Discussion and Conclusions

5. Bibliography

6. Filmography.

\section{Abstract}

In this article we textually analyse some key scenes of Throne of Blood (Kumonosu-jō, Kurosawa, 1957) focusing on how the sinister gradually emerges in the story. As for the concept of the sinister, we follow both the theorization that Freud proposed in his famous 1919 article "The Ominous", as well as the subsequent reading made by Trías proposing some motives for the sinister, which we will be locating in the film, as well as that of González Requena around the same subject. The question that will guide our analysis is whether the sinister arises or returns from the familiar as something repressed, as Freud (and Trías)

points out, or whether, as González Requena claims, the sinister is rather something rejected or challenged. Is there a secret on The Throne of Blood that required remaining hidden in the soul of the protagonist and would be revealed by the influences of the female spider? Or is it the hero himself who, lost by his ambition, falls into the spider web?

\section{How to cite this text:}

Lorenzo J. Torres Hortelano (2021): Motivos de lo siniestro en Trono de Sangre (Akira Kurosawa, 1957) en Miguel Hernández Communication Journal, Vol. 12 (1), pp. 159 a 179. Universidad Miguel Hernández, UMH (Elche-Alicante). DOI: https://doi. org/10.21134/mhcj.v12i.1141 


\section{Introducción}

Es este análisis me propongo investigar cómo lo siniestro va apareciendo y adueñándose del relato en la película Trono de sangre (Kumonosu-jō, 1957) del director japonés Akira Kurosawa. Para ello atenderemos a lo siniestro no solo como categoría estética entroncada con lo bello a partir de Kant y Schelling, sino también a la conceptualización que Freud y, en la actualidad, González Requena, nos ofrecen. Este autor nos avisa de que, efectivamente, no se debe pensar la categoría de lo siniestro exclusivamente como convención artística (2020).

En este sentido, Trono de sangre es un texto muy conveniente tanto para analizarlo desde lo estético -es uno de los films de Kurosawa más logrados estéticamente, donde utiliza de manera más directa eso que en otro lugar hemos denominado poética Zen (Torres, 2006)-, como para analizarlo más allá de lo estético que preconiza González Requena.

Aquí Macbeth, es decir, Washizu, escucha también las dos profecías: una que le hará ocupar el trono y otra que le hará morir si el bosque avanza sobre el castillo. Y en ello tendrá especial relevancia siniestra el ámbito de lo femenino, por las bruja-araña y por la esposa de Washizu, la dama Asaji. En el caso de nuestro film se suma un nivel semántico muy interesante, más si tenemos en cuenta que vamos a analizar lo siniestro: tanto el bosque como el castillo llevan el nombre de la araña.

Teniendo en cuenta que el guion es una adaptación de la tragedia de Shakespeare Macbeth (circa 1606), nuestra hipótesis es que Kurosawa, aunque parte desde el material teatral para ofrecernos un héroe relacionado con lo siniestro en su vertiente más romántica, va apartándose del texto teatral transformándolo a medida que el protagonista cae en su propia ambición azuzada por su esposa, la dama Asaji, surgiendo una red que le atrapa. Es decir, que lo que va germinando es eso que Freud describió, citando a Schelling, como "lo siniestro [...] algo que, debiendo haber quedado oculto, se ha manifestado" (Freud, 1919: 224, de Schelling, 1828-1846). En este caso, ese algo sería la ambición del propio Washizu, si seguimos a Freud (y Trías); pero que también podría ser, en la línea de lo siniestro que señala González Requena, que aún sin esa influencia de la araña, el resultado hubiese sido el mismo.

Mi propósito es argumentar esa hipótesis a partir del deletreo de ciertas secuencias relevantes del film. El criterio principal de selección surge a partir de los cinco motivos sobre lo siniestro que Trías resumiese a partir de su lectura del artículo de Freud Lo ominoso (1919): todos y cada uno de esos motivos tiene su ejemplo cinematográfico en Trono de sangre.

Este film, el decimoctavo de la carrera de Kurosawa, es importante pues está en el centro de su producción del total de 33 películas como director. Esta abarca 52 años, habiendo realizado su primer film en 1943 y el último en 1993 (IMDB, 2020). Lo que nos habla de un momento de transición dentro de su carrera, pero teniendo en cuenta que este proyecto lo llevaba gestando desde mediados de los años 40. Si no lo llevó a cabo entonces fue porque supo que Orson Welles estaba preparando su versión (que finalizaría en 1948), 
por lo que Kurosawa esperó a ver el resultado $\square$ que no le acabó de agradar. Sin duda ello influiría en un hecho aparentemente paradójico: siendo de una de sus películas más analizadas por su perfección técnica y la influencia de la poética Zen, pero, sobre todo, por ser una adaptación de Macbeth, se trata realmente de una versión libre. Era, además, su obra favorita de Shakespeare (Richie, 1970: 115).

$\mathrm{Y}$ decimos aparente porque realmente gran parte de su valor tiene que ver con que no es una mera ilustración de la obra, sino que adapta la obra teatral al medio cinematográfico de una manera muy creativa y, sobre todo, aprovechando todas las técnicas con las que contaba para ello. En este sentido, como sugirió Richie, Kurosawa creó un estilo visual muy potente, como si proviniese de la época muda, lo que sin duda le facilitó su entrada en Occidente (1998: 78). Aunque su lugar destacado lugar en el canon del World Cinema se debe también a la apreciación de su cine como popular y artístico al mismo tiempo, su reconocimiento como cineasta transnacional (la libre adaptación de Shakespeare es el mejor ejemplo) y la presencia en su cine de valores universales (Martin, 2017: 20). Todo ello sin perder la esencia de la "Japanese iconography" (Hutchinson, 2006: 181).

Martinez profundiza en ello al analizar la translación de la obra shakesperiana al contexto japonés,
a society mistakenly assumed to be free of Christian notions of guilt, through the transcultural move of referring to Noh theatre, aligning the story with these Buddhist morality plays. In this manner Kurosawa found a point of commonality between Japan and the West when it came to stories of violence, guilt, and the problem of redemption (2018: 1).

Parece un tema alejado del nuestro principal y, sin embargo, veremos hasta qué punto lo familiar de estos reconocimientos o afinidades es importante en nuestro análisis.

\section{Estado de la cuestión y Método}

Como afirmaba más arriba, parece bosquejarse en el arranque del film un héroe romántico, por su carácter siniestro. En este sentido, ya desde el arranque, se sitúa al héroe en relación dialéctica con la Naturaleza. Como afirma Parker, da la impresión de que en todo el film sea ésta un elemento negativo, muy relacionado con el estado mental del héroe. Además, esto se refuerza por el hecho de que, en el prólogo y epílogo, que parecen discurrir en siglos posteriores, la Naturaleza aparece desolada, como si se tratase de un destino siniestro "with Nature seeming to determine human destruction" (1997: 513). En el mismo sentido, para Schelling la naturaleza es un error distanciado de lo sagrado (1828-1846: 428).

No obstante, la Naturaleza nos puede ser familiar, así una de las ideas mayores de Freud es que lo siniestro puede ser directamente proporcional a la familiaridad que tengamos con aquello que nos da miedo. Para ello, en el artículo "Lo ominoso" (1919) utiliza el término homónimo que analiza lingüísticamente para aclarar su ambigüedad. Nosotros vamos a utilizar el término de lo siniestro, aun siendo conscientes de que éste realmente abarca más niveles o variedades que lo ominoso. Recordemos, pues, que Freud lo relaciona con esa parte 
de lo siniestro que nos angustia porque hace referencia a nuestra memoria, a lo familiar sabido de antiguo o desde hace tiempo. Freud se hace, entonces, la pregunta más lógica: ¿cómo lo familiar deviene lo ominoso? (1919: 224).

$\mathrm{Y}$ bien, en lo que sigue vamos a analizar textualmente, es decir, mediante un análisis cualitativo, deletreando las imágenes, algunas secuencias de la película para comprobar cómo se trata de un ejemplo perfecto para responder a esta pregunta. Para ello atenderemos a la relación entre lo familiar y lo siniestro a través de la peripecia del protagonista, Washizu (Toshiro Mifune) -Macbeth. En este caso, se trata de un texto fílmico que además, en origen, fue teatral. Es decir, un texto que era, en este sentido, también familiar desde antiguo, tanto como la parábola moral sobre los peligros de la ambición extrema, siendo esta última la que llevará a Washizu a cometer los peores crímenes.

El propio Freud empieza su texto sobre lo ominoso relacionándolo con la categoría estética de lo bello y subrayando que la mayoría de los estudios estéticos de la época obviaban las expresiones estéticas ajenas a ésta. Freud, además, lo relaciona con la angustia, de nuevo, una que vamos a localizar muy activamente en nuestro protagonista (íd.).

Conviene recordar que, como Freud comenta, el concepto de lo ominoso (unheimlich) lo toma prestado de Schelling quien, de forma muy original, nos dice que sería "todo lo que estando destinado a permanecer en secreto, en lo oculto, ha salido a la luz" (íd.: 225). Por tanto, será importante atender si en Trono de sangre, igualmente, nos encontramos con un secreto que era necesario tener oculto.

Siguiendo la interesante lectura centrada en el cine que Trías hace de Freud, diremos con el primero que lo siniestro presenta cinco motivos a modo de inventario temático: a) un individuo portador de malos presagios con el que conviene no cruzarse; b) éste puede ser un familiar o un doble; c) apariencia de seres a medio camino entre lo animado y lo inerte, relacionado con la apariencia artística y el erotismo, vínculos con lo familiar, entre lo humano e inhumano; d) efecto de repetición de situaciones idénticas - dejà vu- de tipo horroroso o angustiosas que produce familiaridad placentera pero horrorosa; e) amputaciones, lesiones o descuartizamientos de órganos significativos (ojos, miembro viril) que pueden cobrar vida propia. En resumen, "cuando lo real asume enteramente el carácter de lo fantástico. Podría definirse lo siniestro como la realización absoluta de un deseo (en esencia siempre oculto, prohibido, semicensurado)" (2006: 49-50).

Pues bien, estos cinco indicios y la propia definición de lo siniestro que propone Trías se encuentran de manera evidente en nuestra película y serán subrayados convenientemente durante el análisis. Antes de ello, no está de más recordar una idea de Schelling que nos explica de dónde parte Washizu. Para Schelling, la voluntad inmóvil iniciaría su camino por la que se le muestra (diríamos por la profecía). Sobre este hecho, solo se puede decir que es un factum, es decir, que ha sucedido y que es irreversible, el Archiazar fatal incomprensible. En este sentido, la voluntad es engañada y, por ello, se sorprende por la consecuencia de su acto que es involuntario (1828-1846: 101-102) -en nuestro caso, arrastrada por las arañas femeninas.

En este sentido, Schelling todavía señala una cuestión semántica clave para entender la 
peripecia de nuestro héroe cuando señala que Fatum o fatalidad es también la Fortuna inestable, la primera desgracia (1828-1846: 106) que marcará el destino de Washizu. Es decir, "no hay valores en este Macbeth atado a un círculo de condenación. Podemos considerar así que el personaje de Washizu no tiene voluntad propia, pues el rol que debe desarrollar está ya escrito. La libertad individual, por tanto, tampoco existe” (Pérez, 2007: 224). Analizaremos hasta qué punto esto es cierto en el film.

\section{Análisis y resultados}

Miren este lugar desolado...

donde bubo un orgulloso castillo...

cuyo destino cayó...

en la red de la lijuria de poder...

donde vivía un guerrero fuerte en la lucha...

pero débil ante su mujer...

que le empujó a llegar al trono....

con traición y derramamiento de sangre.

El camino del mal es el camino de la perdición...

y su rumbo nunca cambia.

AQUI YACE EL CASTILLO DE LA TELARAÑA

Así arranca Trono de sangre, mediante un recitado de grave voz en off, similar al empleado en las obras de teatro $N o \bar{c}$. La voz cae pesadamente sobre un paisaje de pura desolación, lleno de brumas y terreno baldío, avanzando pues el lúgubre clima de lo real y de lo siniestro que permea todo el film (Fig. 1) ${ }^{1}$.

Fig. 1 Fotograma de Kumonosu-jō (Kurosawa, 1957). Toho C

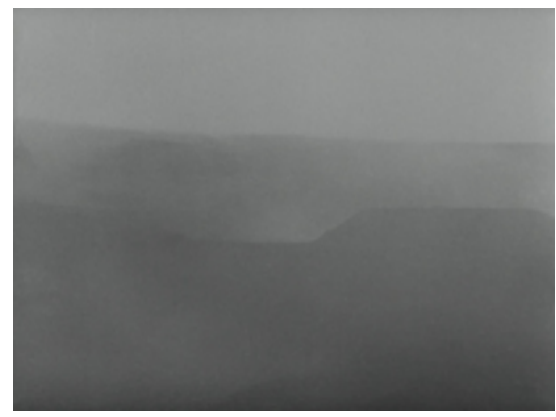

${ }^{1}$ Por motivos editoriales, no podemos insertar todos los fotogramas que nos gustaría, pero pueden encontrarse al completo en este repositorio: https://doi.org/10.6084/ m9.figshare.13332698.v1 


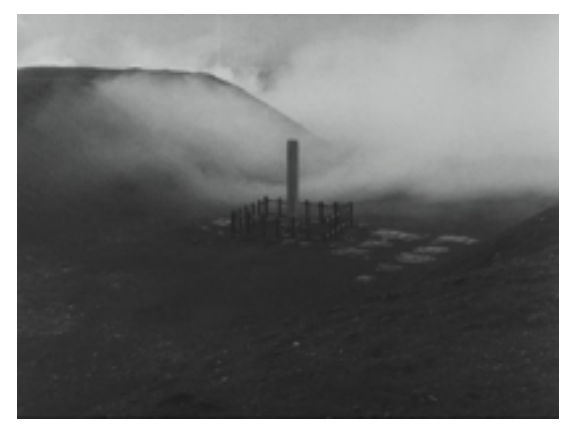

Nada en las imágenes de este epílogo es reconocible o cotidiano, sino más bien cercano a lo abstracto y lo siniestro. No hay formas humanas, sino un desolador vacío. Y ello hasta su tramo final, en el que aparece este elemento arquitectónico, un tótem funerario en el que se lee "Aquí yace el Castillo de la Telaraña". Es decir, que desde un lugar indefinible llegamos a vislumbrar algo que ya nos puede parecer reconocible (cotidiano) pero en línea con lo siniestro y la muerte (Fig. 2).

Desde el principio, pues, se trata de un cuento moral que nos da unas coordenadas para el bien y para el mal, es decir, hace referencia a un tiempo mítico en el que había un castillo con su héroe; pero donde parece que lo que falla es la princesa y, con ella, el guerrero, pues éste es débil. Además, ella no le ayuda a llegar al trono, sino que le empuja a apropiárselo.

Es decir, que el orgulloso castillo se convierte en la telaraña de la princesa antes que en el objeto deseo que el héroe puede conseguir si logra realizar adecuadamente su tarea. Y es que realmente así se titula el film en el original japonés, Kumonosu-jō o "Castillo de la telaraña”, por lo que desde el principio se pone el acento en esa siniestra princesa, o sea, en la araña.

La citada tarea, en el relato clásico, la dona un destinador simbólico, es decir, alguien externo y situado en un eje ético. Sin embargo, aquí el destinador, como hemos señalado, es la propia princesa.

\subsection{Primer motivo: malos presagios}

Siguiendo la propuesta freudiana de Trías, tras el prólogo -realmente un flash-forwarddel film, el relato arranca con cierta tensión, pues los daimyō o señores feudales de la guerra japoneses esperan el resultado de batallas relacionadas con la rebelión contra su autoridad. Un soldado informa que la batalla está en un momento muy delicado y que 
todo queda en manos de Washizu. Aquí parece estar el conflicto de arranque; pero este se resuelve rápidamente, pues la misma escena se repite milimétricamente al tiempo que van llegando las buenas noticias en las que Washizu emerge como héroe -junto con Miki/ Banquo (Minoru Chiaki) -, pues ha sido capaz de romper el asedio.

Sin embargo, continuamos en la valencia negativa en dos sentidos: el héroe lo ha conseguido principalmente con "astucia" (no con "valor" o "fuerza") y se percibe claramente la debilidad del daimyō (el personaje de Duncan en Macbeth), pues su presencia en plano está desequilibrada (F3), no como correspondería a un poder militar y, además, la cámara baja con él para sentarse. Es decir, no parece un orgulloso guerrero que acaba de triunfar, sino que se le nota más bien aliviado. El nimbo sobre su cabeza parece que vaya a cortársela, como si se tratase antes de una nube de mal presagio que de un indicador de prestigio militar del poder.

Sin solución de continuidad, asistimos a una segunda y tercera repetición. Y a una cuarta, en la que se informa que el rebelde suplica la rendición; pero el daimyō, en otra muestra de debilidad al no manifestar clemencia, decreta matarle.

Este primer motivo de malos presagios se ve reforzado por el carácter repetitivo de las escenas que componen la secuencia. En este sentido, Kurosawa lo subraya de manera iterativa mediante un estilema muy común en su cine: una serie cortinillas que desplazan la imagen de izquierda a derecha y que, evitando el montaje por corte, a modo de cesura, nos llevan a la siguiente escena como si pasásemos la hoja de un libro, dotando así de dinamismo a esta secuencia de montaje que implica elipsis de varias horas comprimidas en un tiempo muy corto del relato (Fig. 4). Para ello, aprovecha la entrada de los caballos que, como comprobaremos, se convierten en verdadera fuerza motora del film (Fig. 5).

\subsection{Primera visita a la bruja / araña (motivo de lo inanima- do viviente)}

Washizu y Miki viajan al encuentro del daimyō, pues éste quiere felicitarles y premiarles. En el trayecto hacia el castillo deben atravesar un bosque. Éste produce un efecto de desconcierto sobre nuestros héroes. En este sentido, como afirmaba Freud "lo ominoso sería siempre [...] algo dentro de lo cual uno no se orienta" (Freud, 1919: 221).

Llueve intensamente -la lluvia es en las películas de Kurosawa a menudo un elemento al mismo tiempo intensificador de las acciones y mixtificador de la realidad-, lo que dificulta el avance de los héroes que tienen prisa por llegar hasta su señor. Se equivocan de camino. Vemos formas y sombras de ramas muertas que asemejan siniestras formas (Figs. 6-7) que, por momentos, parecen cobrar vida amenazantemente, efecto reforzado por los relámpagos (Fig. 8), lo que nos avanza el tercero de los motivos relacionados con lo siniestro como cotidiano que señalaba Trías: cómo lo inanimado cobra vida. Como afirma Buket, el espíritu del bosque domina el relato "through the agency of their extensions and substitutes as well—specific natural elements, such as the thunder, lightning, rain, fog, forest, and birds" (2016: 1). 
No es un tema menor en el arte japonés la influencia de las estaciones y del clima. Especialmente en nuestro caso es relevante porque la naturaleza es familiar a los protagonistas, como afirma Shirane (2012: xiv), ésta no se entiende en la cultura tradicional japonesa como opuesta a lo humano, sino como una extensión — podemos decir, entonces, es una cercanía familiar, que, por cierto, subraya el aspecto romántico de nuestro héroe. En este sentido la lluvia perenne, tan querida por Kurosawa, en japonés, samidare, tiene cierta homofonía con midare, es decir, afligido (Íd.: 39). Es decir, que desde la propia tradición vernácula, lo inanimado — en este caso la lluvia — muestra su relación con lo viviente, pero con esa valencia negativa de espíritu romántico atormentado.

Como iremos viendo, varios motivos se cruzan al mismo tiempo. En este caso, también el de la repetición cuando nuestros héroes se dan cuenta de que han cruzado dos veces por el mismo sitio. Las huellas de los caballos lo indican. Están en el Bosque de las Telarañas -que vendría a ser el bosque de Birnam shakespeariano. Es decir, que ya se relaciona desde el principio al bosque con lo siniestro y con algo que tiene que ver con la imposibilidad de avanzar. Washizu lo recalca: - "Algo nos impide avanzar". Miki se ríe pues eso despistaría a un enemigo y presume de que ellos saben todos los caminos.

Es decir, se sienten familiarizados con el bosque y con lo que éste tiene de siniestro. Será pues, culpa de la llwvia (es decir, siguiendo lo que he comentado más arriba, por culpa de tener las emociones a flor de piel). Para relajarse, Washizu lanza flechas contra bosque, podríamos decir, a la gran araña: esas flechas se multiplicarán por cientos contra él en la secuencia final de la película. De momento, el bosque le devuelve unas metálicas y siniestras carcajadas: “¿Un espíritu maligno?” pregunta Washizu. No importa, nuestros héroes blandirán sus lanzas y flechas contra éste.

En su quijotesco ataque, llegan hasta el origen de las carcajadas, el espíritu maligno, al que podemos llamar también, bruja-araña -que representa las tres brujas de Macbeth. Más adelante encontraremos otra araña, esta vez humana, la esposa de Washizu, la dama Asaji (Isuzu Yamada), también portadora, como la bruja, de malos presagios. Ambas se convierten en destinadoras siniestras de la tarea torcida de nuestro héroe pues, no lo olvidemos, pese a las apariencias, nos encontramos ante un relato clásico. El problema es que desde el principio el camino de Washizu está marcado por la espiral mortífera de la telaraña que le hará pasar de héroe a asesino.

Desde antes de ver a la bruja-araña, ya intuimos su carácter arácnido, pues sabemos que está ahí escondida tapada por un árbol. Además, la cabaña donde espera ya se asemeja al cuerpo erguido de una araña de muchas patas (Fig. 9).

Todo esto se confirma en cuanto nuestros héroes se acercan cautelosamente. Se trata sin duda de una araña, pues teje también su hilo (Fig. 10); pero no una cualquiera, pues esa rueca, por el papel que va a tomar esta bruja-araña es, a modo de bola de cristal, una rueda del tiempo o de la Fortuna. Como nos recuerda Mcdonald al relacionar el rostro de la bruja con la máscara del personaje femenino de la obra de teatro Nob Kurozuka [Montículo negro] ${ }^{2}$, éste tiene el poder sobrenatural de adivinar el futuro y los secretos más oscuros

2 Tan negro como el paisaje desolado del inicio del film. 
del alma humana $(1994,129)$. Pero quizá el que mejor ha explicado la función de esta rueca es Harrison:

a graphic representation of the Buddhist wheel that inexorably links birth to death, Kurosawa shows that human desire for power is an entrapment, thereby explicating the cause of suffering as a psychological attachment to mastering the revolving physical world (2017: 49).

Por otra parte, antes de ver por primera vez a la bruja oímos otro canto similar al del arranque del fim que continua ese nivel moral tan habitual en las películas de Kurosawa:

Todos los hombres son vanidosos.

Y la vida no es más que una cadena efimera, una atadura de la que los nombres intentan liberarse.

Para demostrar lo débiles que son los mortales.

Porque la vida es como una flor que florece y luego se marchita en la tumba.

La carne, con palabras y actos refleja la lijuria y avaricia de los mortales.

Y los hombres acumulan el pecado hasta llegar al inexorable juicio.

Cuando el orgullo del vencedor y la mancha del perdedor, no salvarán ni al santo ni al pecador.

Y la carne sana al vil bendecirá. Y luego en la nada se desvanecerá.

Cabe subrayar en este recitado algunos elementos que casan con el campo semántico de la telaraña: "cadena efímera" y "atadura de la que los nombres intentan liberarse" que parecen convertirse en las imágenes principales de este recitado de la bruja-araña.

En este sentido, no olvidemos que este nivel moral no deja de ser el sentido tutor, lo que desde la superficie del texto dirige la conciencia del espectador haciéndole reconocible los más elemental de lo que ahí se juega. Pero si queremos llegar al fondo de lo que nos espera en la experiencia estética de esta película, tenemos que saber espurgarlo e ir a lo fundamental, es decir, por qué y cómo nuestro héroe cae en la telaraña, pues no parece que sea ese sentido tutor moral el que atrae a Washizu y Miki hasta ahí. Lo que buscan, realmente, es oír lo que no está en esa superficie familiar de lo moral y reconocible, sino en sus ambiciones más profundas e inefables.

Esto parece preguntarse Ramos: “¿Es la profecía la causa o sólo el detonante «mágico» de unas acciones usurpadoras que tarde o temprano estallarían en el alma de Washizu con el acicate de su esposa, auténtico brazo ejecutor?". Ramos señala que ni el film ni en la obra teatral hay respuesta a tal pregunta (2010: 209): también por ello ahí se halla el punto de ignición de ambas obras, la interrogación que nos hace volver a ellas, pero sin obtener respuesta. Como ya hemos analizado en otro lugar, este tema de la verdad sobre las motivaciones de los personajes de Kurosawa es un lugar común en su filmografía, relacionado además siempre con ciertas transgresiones que pueden llevar a la muerte (Torres). 


\subsection{Tercer motivo (I): araña humana}

Los bravos guerreros se aproximan, con todo tipo de precauciones, tensos, hasta la madriguera de la bruja-araña. Lo primero que le pregunta Washizu es quién es ... ¿un ser humano o un espiritu maligno? Aquí tenemos de nuevo el tercer motivo, ya saben, seres a medio camino entre lo inanimado y lo inerte, entre lo humano e inhumano.

La bruja-araña le cuenta la profecía: Washizu se convertirá en el Señor de la Mansión del Norte y, un día, en el del Castillo de las Telarañas (el más importante). Washizu se lo toma a broma, pero no pierde su tensión. Ella, adulando y atizando su vanidad, cred que le gustaría saberlo y le azuza: ¿él no es capaz de tomar el mando?

Washizu le amenaza, pero Miki cree que la bruja-araña no puede estar hablando en vano. Éste también recibe su premonición: tomará el mando del Fuerte Uno (el que comandaba hasta ese momento Washizu). Miki quiere saber más: luego la suerte le abandonará, pero durará más que la de Washizu pues, finalmente, el hijo de Miki se convertirá en el señor del Castillo de las Telarañas.

Fig. 11 Fotograma de Kumonosu-jō (Kurosawa, 1957). Toho @

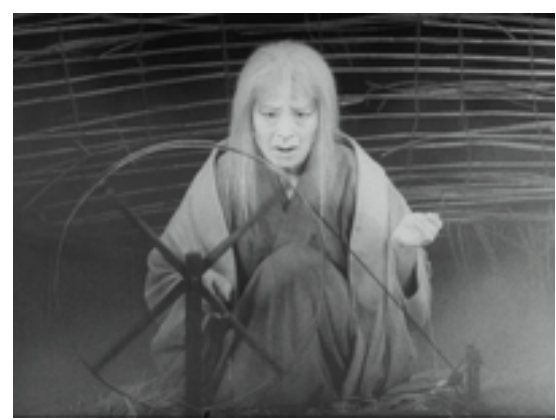

Fig. 12 Fotograma de Kumonosu-jō (Kurosawa, 1957). Toho C

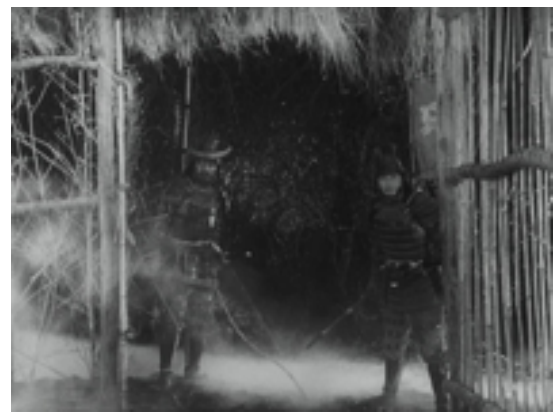

En todo este diálogo los bravos guerreros se ven empequeñecidos frente a ella, que domina el plano mientras gira su rueca (Fig. 11). Ella ha ido tejiendo su red en la que ya han caído 
los guerreros, hasta que desaparece por arte de magia. En la mirada de ellos se percibe el desconcierto y estupor por lo que acaban de oír y presenciar. Y, lo más relevante: su mirada ha quedado atrapada dentro de la madriguera de la araña, o más directamente, ya se han enredado en la telaraña cómo lo indica el hecho de que sus armas están bajadas (Fig. 12).

Y no se puede dudar de que la madriguera es la de una araña mortífera pues está rodeada de los esqueletos de decenas de guerreros (Fig. 13).

\subsection{Tercer motivo (II): ¿a qué suena una araña?}

Macbeth y Trono de sangre comparten una especie de mayeútica por la que sus protagonistas creen que el destino que les cuentan las brujas está escrito porque lo merecen. Quizá éste es uno de los mayores aciertos del film, aunque ya está en la obra teatral, me refiero a que se introduce el elemento fantástico de la brujería, del oráculo siniestro, para que inconscientemente el espectador se vaya dando cuenta de que todas esas premoniciones suponen la propia ambición de Macbeth y Washizu: la clave es que hasta ese momento había una Ley que les hacía sostener y gestionar esa ambición para el bien común.

Por tanto, la bruja, lo que ésta supone, está realmente en sus almas, carcomidas éstas por una araña silenciosa. En este sentido calguna vez se han preguntado cómo suena una araña si es que ésta produce algún sonido?

Ni siquiera el gran Shakespeare podría haberlo representado en los ruidosos teatros isabelinos, sin embargo Kurosawa fue capaz, aprovechando el sutil sonido del kimono de la esposa de Washizu, la dama Asaji (Lady Macbeth) rozando apenas el tatami ${ }^{3}$ (Fig. 14). Ese es el escalofriante sonido siniestro de la araña. Se trata de otro de esos momentos memorables de Macbeth que Kurosawa recrea: cuando la dama Asaji lleva saké mezclado con droga que adormecerá a la guardia del daimyō. Es decir, el momento previo el que se producirá el peor de los hechos (the deed), el hecho de los hechos, la aniquilación de la Ley, la consumación de la ambición del Washizu que, por cierto, recibe el arma homicida de manos de la araña (F15) y, por ello, cómo señalábamos más arriba, es su destinadora siniestra.

Este sonido de su kimono, junto con el de sus tabi ${ }^{4}$ y la apariencia de su rostro nos recuerda al teatro $N \bar{o}$-al igual que la apariencia de la bruja-araña-, en el que los personajes femeninos suelen ser fantasmas que portan máscaras características y que se repiten de obra en obra ${ }^{5}$. Se refuerza de este modo este tercer motivo a medio camino entre lo humano y lo inhumano.

Kurosawa sabiamente deja el hecho siniestro en fuera de campo, pero no por una cuestión

${ }^{3}$ Código de tiempo: 00:42.14.

${ }^{4}$ Los tabi son calcetines tradicionales japoneses que utilizan indistintamente hombres y mujeres. Son comúnmente utilizados con los kimonos y generalmente de color blanco.

${ }^{5}$ En concreto, Kurosawa está influenciado por el subgénero dentro del Nō, el shuramono, en el que los fantasmas son famosos guerreros que reviven la violencia pasada con la esperanza de la redención. 
de censura o por evitar mostrar la sangre, sino porque es la mejor manera de ver quién dirige la mano del asesino; esa araña cuyo deseo está polarizado en la sangre.

Si en Macbeth la señal que da pie son las campanadas de medianoche, aquí será el graznido de unas aves de mal agüero ${ }^{6}$. E, igualmente, deja el asesinato del daimyō fuera de campo, lo que dota de una mayor potencia siniestra a ese acto y, sobre todo, concentra en la araña-dama la realización intelectual de este asesinato.

La dama Asaji es mostrada hierática, enmarcada por dos enormes manchas de sangre en la pared del fondo y en el suelo fondo, prueba de otro crimen, el del antiguo señor del castillo, ajusticiado como traidor por Washizu. Además, las flechas parecen salir de su cuerpo (Fig. 16): otra muestra del poder de la telaraña y, sobre todo, una premonición del asaetamiento final de Washizu.

\subsection{Quinto motivo (I): amputaciones}

Pese a ir cumpliéndose la profecía, o por ello mismo, Washizu está intranquilo, pues sabe que el hijo de Miki, como ésta predecía, puede ser en última instancia el daimyō principal. Por ello manda matar a ambos; pero el samurái encargado de la tarea solo lo logra con Miki. Como prueba, trae la cabeza de este último (Fig. 18).

El samurái, a su vez, será asesinado cruelmente por Washizu por dejar escapar al hijo de Miki, formándose a partir de ello un amplio reguero de sangre. Mientras agoniza, parece revivir por momentos mientras clama piedad. Esto hace retroceder a Washizu que mira aterrorizado al samurái agonizante, evidentemente, recordando el hecho siniestro principal. Todo ello se relaciona con el quinto motivo señalado por Trías en el que se dan amputaciones que parecen cobrar vida (Fig. 19).

Fig. 19 Fotograma de Kumonosu-jō (Kurosawa, 1957). Toho C

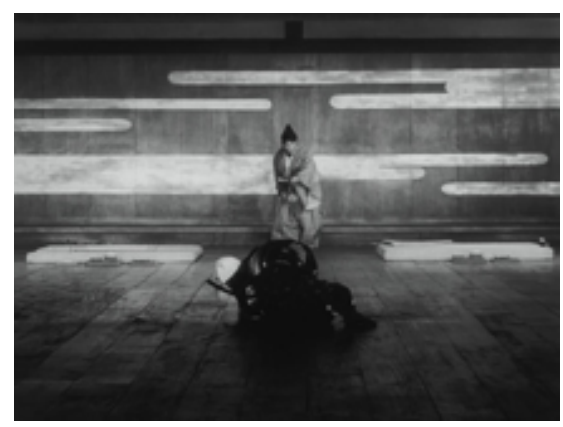

${ }^{6}$ Este mal augurio se repetirá hacia el final, en el previo a la batalla definitiva, cuando unas aves similares se metan en la sala del castillo donde la preparan (código de tiempo: 01:36:51). Alguno de los planos de esta secuencia, tan cercanos que las aves parecen manchas negras, seguramente influenciaron al Hitchcock de The Birds que es solo seis años posterior a nuestro film. 


\subsection{Cuarto motivo: dejà vu}

Volvamos por última vez a la dama Asaji, la cual había quedado embarazada, pero que aborta espontáneamente. Esto, unido a la situación de Washizu, la lleva al borde la locura. Así, justo antes de la batalla final, empieza a lavarse las manos compulsivamente.

Ya analicé más arriba cómo ella es la encarnación del destino de Washizu: ¿es, por tanto, la figura femenina la que lleva a nuestro héroe al desastre? Pues no del todo ya que ella tendrá un último atisbo de mala conciencia o, más bien, como vengo detallando, va a percibir, a través de esa sangre imaginaria que mancha sus manos algo demasiado familiar y siniestro. Me refiero al momento en el que justo antes de la batalla final empieza a lavarse las manos de forma compulsiva y temblorosa (Fig. 17): "Me lavo y me lavo, pero la sangre siempre permanece. Y el olor también ¿Jamás volverán a estar limpias mis manos?”

Fig. 17 Fotograma de Kumonosu-jō (Kurosawa, 1957). Toho ㄷ

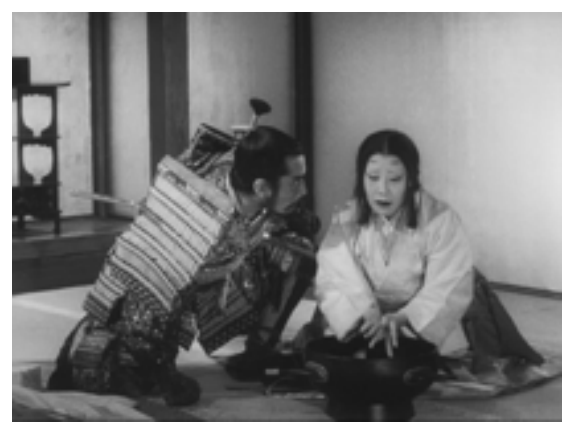

Este acto de lavarse las manos ya se había producido en la escena del asesinato del daimyō, por lo tanto, asistimos a otra repetición o dejà vu; no obstante, como he señalado, en este caso, las manos de lady Asaji tiemblan. Pero no es el único motivo siniestro que surge aquí pues, al mismo tiempo, Washizu se aproxima a ella y adopta su postura. La mira intensamente a los ojos, como intentando comprender su locura; pero este gesto de abismamiento por parte de Washizu también es un mirarse así mismo, a su propia alma oscura. Todo ello nos lleva a pensar en unos dobles familiares (segundo motivo).

Este motivo de la repetición siniestra es un tema mayor durante todo el film pues, como afirma Richie, es como si el entretenimiento tan familiar que propone el film se convirtiese en un comentario: nuestros héroes entrando y saliendo de la niebla y la lluvia, los guerreros muertos alrededor de la madriguera de la bruja-araña (sus fantasmas) que son víctimas de ésta, como lo es Washizu, el coro al principio y al final del film, las diferentes batallas, las dos vistas del castillo en ruinas... "all this suggests repetition and the same actions endlessly, mindlessly repeating themselves" (Richie, 1970: 120). 


\subsection{Tercer motivo (III): cuando el bosque camine.}

En su segunda visita a la bruja-araña Washizu quiere saberlo todo. Ésta le avisa que solo perderá una batalla si el bosque empieza a caminar. Esta mágica y siniestra imagen que solo podía crear el genio de Shakespeare es recreada a su vez por Kurosawa, como mostraré enseguida, de forma magistral.

Antes, cabe recordar que Freud, en su citado artículo "Lo ominoso", cita una escena del cuento de Hoffman El hombre de arena (1919: 229). El diálogo real es como sigue:

- ¿Ves aquel arbusto que se agita allá abajo? -decía Clara-. Diríase que viene hacia nosotros.

Nataniel, mecánicamente, buscó en el bolsillo el anteojo de Coppola. Clara estaba delante del cristal. Entonces Nataniel sintió que su pulso latía rápidamente y que su sangre hervía en sus venas; pálido como la muerte miró a Clara y sus ojos tenían siniestra expresión. Saltó como un tigre, profiriendo un grito ronco y feroz: «iMuñeca de madera, vuélvete... muñeca de madera, vuélvete!», y después, cogiendo a la joven con fuerza convulsiva, quiso arrojarla desde la plataforma (Hoffman, 1816: 87).

Este motivo de un elemento inanimado que cobra vida es quizá el que más nos evoca esa familiaridad que se vuelve siniestra. La clave más allá de esa vivificación viene dada por otros dos elementos: un punto de vista que implica cierta distancia desde una lejanía; y el hecho de que el arbusto, el bosque, se mueva hacia el que mira. Incluso podría pensarse que en el caso del cuento de Hoffman todo se debe a un efecto visual provocado por la distancia y la altura, que no por ello produce un resultado menos siniestro.

Si atendemos al estilo visual general del film, nos daremos cuenta de que esta distancia se ve reforzada por el uso predominante de plano abiertos, tendentes al plano general. Podemos ver aquí de nuevo la influencia del Nō, donde usualmente todo se ve al completo. De esta manera, se pude observar mejor como el espacio, todo lo que rodea a Washizu le atrapa como si se tratase de una tela de araña. La única excepción es la secuencia final que paso analizar, en la que los planos cortos predominan.

En el caso de Trono de sangre se percibe claramente que el bosque se mueve, ayudado por el hecho de que el encuadre (Fig. 20) es muy corto, pese a que esperaríamos un plano general. Ello es debido a que pese a que Washizu está en lo alto de una torre (como los personajes de Hoffman), al mirar a través de una claraboya, se cierra y enfoca el motivo y se subraya, entonces, su punto de vista (se trata de planos subjetivos). No es, pues, una mera ilustración de ese pasaje de Macbetb; además, la secuencia se convertirá en todo un despliegue de los diferentes motivos siniestros que hemos ido localizando, subrayado por el uso de la cámara lenta.

El bosque, efectivamente, se mueve hacia el Castillo de la Tela de Araña. Es el ejército del hijo de Miki, al que la profecía situaba como señor del castillo y que Washizu no consiguió 
asesinar. Dos planos similares muestran ese desplazamiento adornado de niebla, pero significativamente, no hay un tercero.

F20 Fotograma de Kumonosu-jō (Kurosawa, 1957). Toho (C)

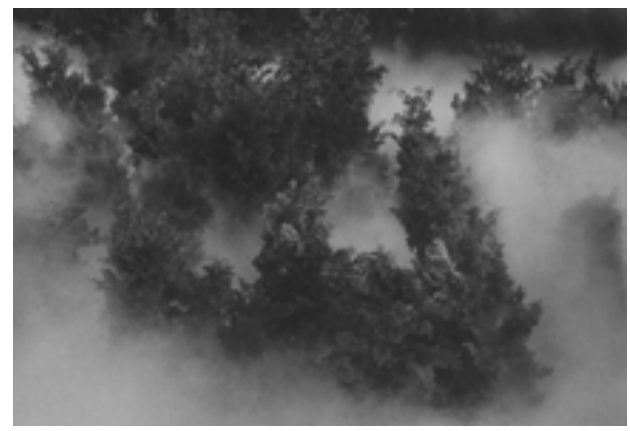

Previo a este momento de ignición Washizu, para animarse y seguro de su triunfo, les relata a sus samuráis el encuentro con la bruja-araña, es decir, revela su secreto: que es invencible dado que un bosque no puede caminar. Mientas que la araña es silenciosa, este samurái, literalmente, va a morir por la boca, o más bien por la garganta como veremos enseguida. Y es que como señalaba Trías y cité al principio, lo siniestro ocurre "cuando lo real asume enteramente el carácter de lo fantástico [...] como la realización absoluta de un deseo (en esencia siempre oculto, prohibido, semicensurado)" (2006: 49-50).

Así, cuando los soldados ven que el bosque empieza a caminar, se refugian despavoridos en el castillo y empiezan a lanzar flechas contra su señor, pues se dan cuenta de que él es la causa del problema. Se inicia así una de las secuencias, si cabe, más maravillosamente rodadas por Kurosawa y con una de las mejores interpretaciones de Mifune, en la que su característico histrionismo cobra todo su sentido. Me refiero a la secuencia del asaetamiento de Washizu, el cual se verá rodeado paulatinamente de cientos de flechas, como si fuese una tela de araña que no le dejase escapar y que va atrapando y malhiriendo su cuerpo.

Fig. 21 Fotograma de Kumonosu-jō (Kurosawa, 1957). Toho C

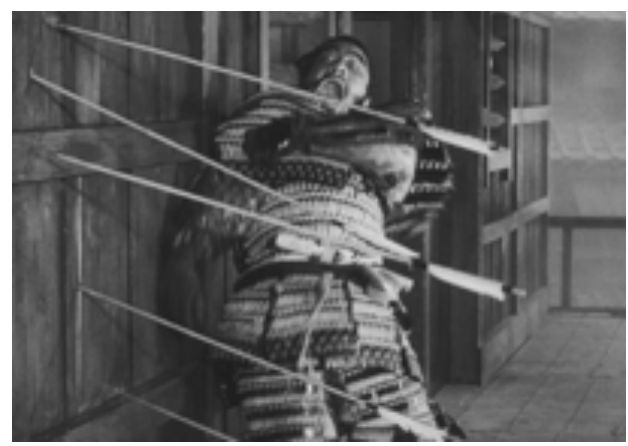


Fig. 22 Fotograma de Kumonosu-jō (Kurosawa, 1957). Toho ㄷ

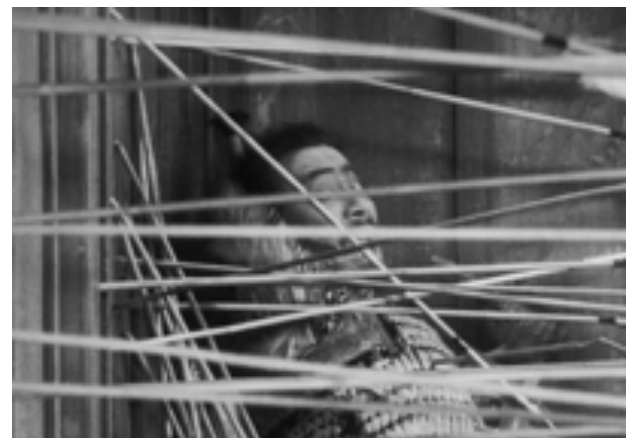

Sin embargo, Washizu, porque parece que no acaba de morir, como si de un martirologio barroco de Ribera o Rembrandt se tratase, mostrando la fugacidad de su poder (Álvarez, 2018: 146), es él mismo el motivo siniestro de un ser inanimado que revive. $\mathrm{Y}$ es que pese a las decenas de flechas que atraviesan su cuerpo, será una sola de éstas la que acabe definitivamente con su vida, una que le atraviesa la garganta (quinto motivo de lesiones de elementos vitales), que es por donde simbólicamente se avanzaba su muerte al contarles a sus soldados su secreto (Fig. 23) y subrayado por el cese momentáneo de todo sonido en la banda sonora. También recuerda aquella flecha del principio del film que lanzaba al bosque y que éste respondía con una carcajada metálica.

Fig. 23 Fotograma de Kumonosu-jō (Kurosawa, 1957). Toho C

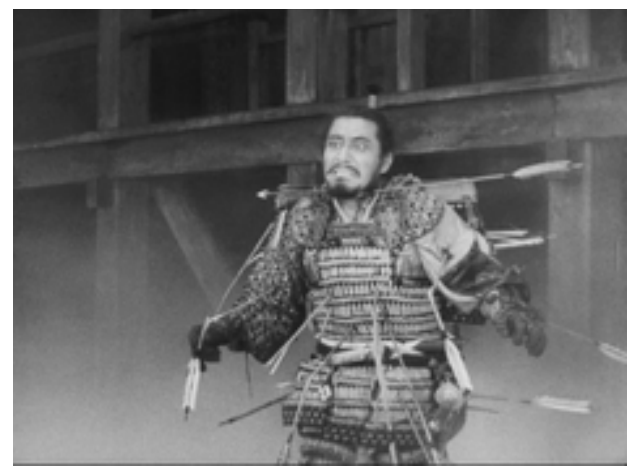

\subsection{Discusión y Conclusiones}

Washizu es en el fondo un ingenuo (al contrario que Macbeth), pues "no puede ver las consecuencias de sus acciones, porque el mal le llegó de fuera y él es ajeno a éste” y cree dominar la ambición, pero ésta se apodera de él (Guaraglia y de Nigris, 2018: 20). Hasta el punto de que podemos concluir con que realmente lo que representa Washizu en el relato es destruido por eso que nos hace "humanos": las palabras, como alguien que no ha 
sabido darles su valor. Y, sobre todo, es que la palabra es lo que da forma y mantiene la Ley Simbólica. Por lo tanto, esa pregunta que teníamos pendiente acerca de si todo se debe a un destino fatal (porque algo debía permanecer oculto, es decir, siguiendo a Freud y a Trías) o, como argumentaba en mi hipótesis, es la propia ambición desmedida de Washizu la que le lleva a caer en lo siniestro (en la línea teórica de González Requena) queda pendiente.

Seguramente ambas cuestiones se cruzan lo que, tratándose de un texto poético, no debe extrañarnos, pues este tipo de textos tiene la capacidad de convertir ciertas preguntas que sobrevuelan el texto en verdaderas interrogaciones que apelan a nuestras emociones más profundas y problematizan nuestra relación con el héroe.

En todo caso, si atendemos por última vez al nivel moral del film, la ambición es algo familiar al ser humano, pero que debe permanecer oculto, es decir, que debe ser gestionado por una Ley Simbólica. De esta manera, Trono de sangre acaba todavía de manera más pesimista que Macbeth. Pero no por ello es un texto menos enraizado en el relato clásico, ya que el héroe, por muy sinestro que sea, es finalmente ajusticiado, además, de la manera más laberíntica, pues, como hemos analizado, es él mismo el que firma su sentencia de muerte.

Siguiendo a Trías lo siniestro aparece en el film por la realización absoluta de un deseo (2006: 49-50), en nuestro caso cristalizado en la ambición de Washizu. Una ambición que permanecía oculta, censurada y gestionada por la Ley Simbólica y que la araña se encarga de desmontar, al tiempo que teje la trampa mortal para el héroe.

\section{Bibliografía}

Álvarez, R. (2018). Claves de la pintura barroca en el cine en blanco y negro de Akira Kurosawa. Fotocinema, 16, 127-151.

Freud, S. (1919). "Lo ominoso", Obras Completas Vol. XVII. Buenos Aires: Amorrortu, 1989.

Buket, A. (2016). The Reception of the Weird Sisters in Welles's Macbeth and Kurosawa's Throne of Blood. The Asian Conference on Film and Documentary 2015: Official Conference Proceedings. Recuperado de: https://papers.iafor.org/proceedings/ conference-proceedings-filmasia2015/

González Requena, J. (1997). Emergencia de lo siniestro. Trama y Fondo, 2, pp. 50-70.

--(2020). Seminario “Conceptualización psicoanalítica”, Máster en Psicoanálisis y Teoría de la Cultura, Universidad Complutense de Madrid. Recuperado de: http://gonzalezrequena. com/asignaturas/conceptualizacion-psicoanalitica/

Guaraglia, M. y de Nigris, P. (2018). Entre Shakespeare y Kurosawa: Lecturas comparativas de la tragedia de Macbeth y Trono de sangre. Sic, 8, 20, p. 42-49. Recuperado de: http://www. cajaderesonancia.com/archivos/Alejandra $\% 20$ Dopico $\% 20$ sobre $\% 20$ Luis $\% 20$ Bravo $\% 20$ Revista $\% 20$ Sic.pdf\#page $=42$ 


\section{MHCJ Vol. 12 (1) | Año 2021 - Artículo n 8 (175) - Páginas 159 a 179 - mhjournal.org}

Harrison, K. (2017). Shakespeare, Bakbtin, and Film. A dialogic Lens. Switzerland: Palgrave Macmillan, http://doi:10.1007/978-3-319-59743-0

Hoffman, E. (1815). “El hombre de arena”. En Cuentos, Madrid: Alianza, 2002.

Hutchinson, R. (2006). "Orientalism or Occidentalism? Dynamics of Appropriation in Akira Kurosawa.” En Ed. Stephanie Dennison and Song Hwee Lim, (pp. 173-87). Remapping World Cinema: Identity, Culture and Politics in Film. Londres : Wallflower.

IMDB (2020). "Akira Kurosawa", Recuperado de: https://www.imdb.com/name/ nm0000041/

Martin, D. (2017). Subtitles and Audiences: The Translation and Global Circulation of the Films of Akira Kurosawa. Journal of Film and Video, 69(2), 20-33. https://doi:10.5406/ jfilmvideo.69.2.0020

Martinez, D. P. (2018). From 'Scottish' Play to Japanese Film: Kurosawa's Throne of Blood. Arts, 7, 50; https://doi.org/10.3390/arts7030050 Reeditado en Eds. Centeno-Martín, M. \& Morita, N. 2020), Japanese Transnational Cinema, Basel: MDPI. Recuperado de: https:// www.mdpi.com/books/pdfdownload/book/2921

Mcdonald, K. I. (1994). Japanese Classical Theater in Films, Londres: Associated University Press.

Parker, B. (1997). Nature and Society in Akira Kurosawa's Throne of Blood, University of Toronto Quarterly, 66, 3. Pp. 508-525.

Pérez, R, (2007). Macbeth en el Castillo de la Tela de Araña. Akira Kurosawa. Comunicación: revista Internacional de Comunicación Audiovisual, Publicidad y Estudios Culturales, 5, 2007, pp. 221-226.

Ramos Ateaga, J. A. (2010). De providentia et chaos: Trono de sangre de Akira Kurosawa: (Kumonosu jo, Akira Kurosawa 1957). Revista Latente: Revista de Historia y Estética del Audiovisual, 8, pp. 206-210. Recuperado de: https://riull.ull.es/xmlui/bitstream/handle/915/13318/ LT_08_\%282010\%29_40.pdf?sequence=1\&isAllowed $=\mathrm{y}$

Richie, D. (1970). The Films of Akira Kurosawa. Berkeley: University of California Press.

Schelling, F. W. J. (1895). Filosofía del arte. Madrid: Editorial Tecnos, 2012.

Schelling, F. W. J. (1828-1846). Einleitung in die Philosophie der Mythologie. Stuttgart: J.G. Cotta'scher Verlag.

Shirane, H. (2012). Japan and the Culture of the Four Seasons. New York: Columbia University Press.

Torres Hortelano, Lorenzo J. (2006). Primavera tardía de Yasujiro Ozu: cine clásico y poética Zen. Valladolid: Caja España.

Torres Hortelano, Lorenzo J. (2020). Images for the paper: Reasons for the sinister in 
MHCJ Vol. 12 (1) | Año 2021 - Artículo no 8 (175) - Páginas 159 a 179 - mhjournal.org

Throne of Blood (Akira Kurosawa, 1957), figshare. Figures. https://doi.org/10.6084/ m9.figshare.13332698.v1

Trías, E. (2006). Lo bello y lo siniestro. Buenos Aires: Editorial Ariel.

\section{Filmografía}

Motoki, S. \& Kurosawa, A. (productores) y Kurosawa, A. (director) (1957). Kumonosu-jö/ Trono de sangre [cinta cinematográfica]. Japón: Toho.

Hitchcock. A. (productor y director) (1963). The Birds/Los pájaros [cinta cinematográfica]. EEUU: Universal Pictures.

\section{Uso de imágenes}

Las imágenes utilizadas como figuras en este artículo son elementos centrales del análisis, realizado únicamente con fines científicos en el ámbito académico 
MHCJ Vol. 12 (1) | Año 2021 - Artículo no 8 (175) - Páginas 159 a 179 - mhjournal.org

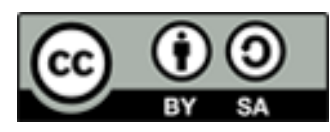

Licencia Creative Commons

Miguel Hernández Communication Journal

mhjournal.org

\section{Cómo citar este texto:}

Lorenzo J. Torres Hortelano (2021): Motivos de lo siniestro en Trono de Sangre (Akira Kurosawa, 1957) en Miguel Hernández Communication Journal, Vol. 12 (1), pp. 159 a 179. Universidad Miguel Hernández, UMH (Elche-Alicante). DOI: https://doi. $\operatorname{org} / 10.21134 /$ mhcj.v12i.1141 